\title{
EXPERIENCE WITH PERFUSION HYPOTHERMIA USING AN IMPROVED ROTATING DISC OXYGENATOR*
}

BY

\author{
FRANK GERBODE, JOHN J. OSBORN, AND J. BRUCE JOHNSTON†
}

From the Departments of Pediatrics and Surgery, Stanford University School of Medicine, Stanford, California, and the San Francisco Institute of Medical Sciences, Presbyterian Medical Center, San Francisco, California

(RECEIVED FOR PUBLICATION JUNE 29, 1960)

Cooling the living organism slows the rate of the metabolic processes. Bigelow, Lindsay, and Greenwood (1950) showed that one effect of hypothermia was that an animal would survive for a longer period when deprived of its circulation. For the first time, therefore, it became possible to shut off the circulation completely, open one of the chambers of the heart, and repair certain intracardiac abnormalities (Lewis, Varco, and Taufic, 1954; Swan, Zeavin, and Blount, 1953). Serious obstacles were soon met when attempts were made to extend the application of this principle in the treatment of more complicated defects. If the surgeon required more than eight or 10 minutes of circulatory occlusion, he found himself sailing between Scylla and Charybdis, for prolonging the period of circulatory occlusion resulted in permanent damage to the central nervous system and further lowering of the temperature inevitably caused ventricular fibrillation.

A wealth of time and effort has been spent in trying to overcome fibrillation associated with hypothermia, but, although a new ray of hope appears every few months, there is still no certain method of preventing it. Thus the early promise of hypothermia was not immediately fulfilled, and attention continued to be focused on the development of extracorporeal circulation. In the past five years the pioneering work of Miller, Gibbon, and Fineberg (1953) and many others has gone forward on many fronts, resulting in the development of cardiopulmonary bypass systems which are highly efficient and which carry minimal risk to the patient when employed by expert teams.

And yet the enthusiasts of hypothermia were not idle. The direct attack on ventricular fibrillation had failed for the moment, but recently an outflanking manœuvre has made it possible to deal with this hazard. The heart was apparently the weak link in

\footnotetext{
Aided in part by grants from the U.S. Public Health Service and the American Heart Association.
}

the chain. Yet it was realized that the heart was nothing more than a pump, and good pumps were now available. By appropriate cannulation of both sides of the heart, using two pumps, with a heat exchanger inserted in one or the other circuit and making use of the subject's own lungs for ventilation, Shields and Lewis (1959) and Drew, Keen, and Benazon (1959) demonstrated in the laboratory that it was possible to continue cooling to a very low temperature, reducing the function of the heart to that of a mere channel for the passage of blood and ignoring the fibrillating ventricle. This technique has been carried into the clinical field with considerable success by Drew and Anderson (1959), who found that at $15^{\circ} \mathrm{C}$. they could safely deprive the body of its circulation for as long as an hour.

\section{HYPOTHERMIA USING AN OXYGENATOR}

The authors have become increasingly interested in hypothermia, not so much as the means itself, but rather as an adjuvant to perfusion for safer surgery on the more complex lesions. The earlier oxygenators used in this unit were either of the standard rotating disc or modified Gibbon design (Gerbode, Osborn, Melrose, Perkins, Norman, and Baer, 1958). Although their performance was adequate in dealing with smaller patients it was usually difficult to achieve a satisfactory flow rate in larger patients, for when high outputs were attempted, either anoxia or foaming became serious problems. To eliminate these difficulties, a new oxygenator was designed, incorporating the following principles. The basic concept of multiple rotating discs was retained but a much larger disc diameter was chosen, so that only the outer portion would be filmed with blood. This produced the same oxygenating surface as the standard current disc oxygenator, but required a much smaller priming volume 


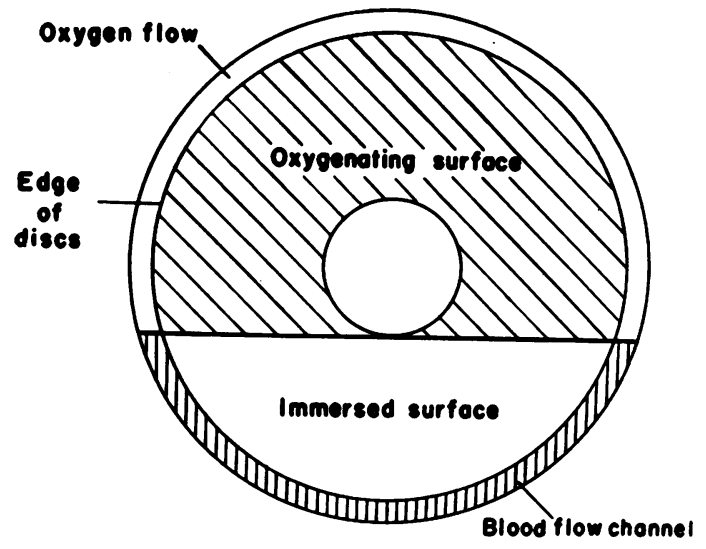

FIG. 1.-Diagram of disc from standard rotating disc oxygenator showing relationship of size of disc to oxygenating surface.

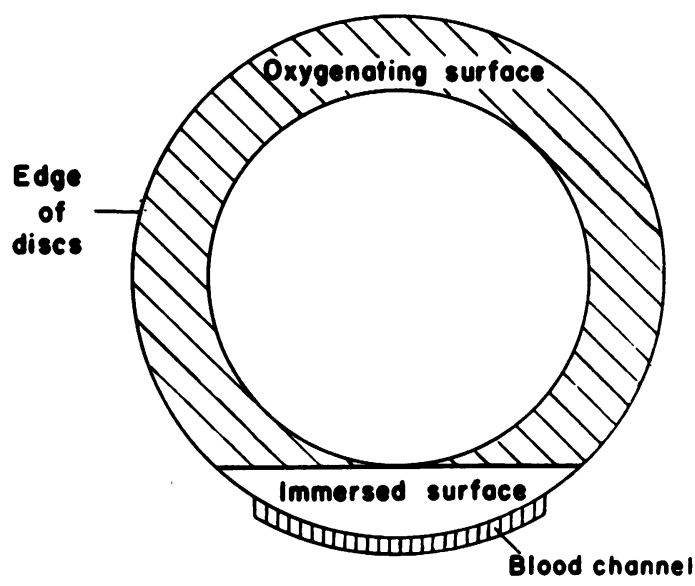

FIG. 2.-Similar diagram from modified rotating disc oxygenator.

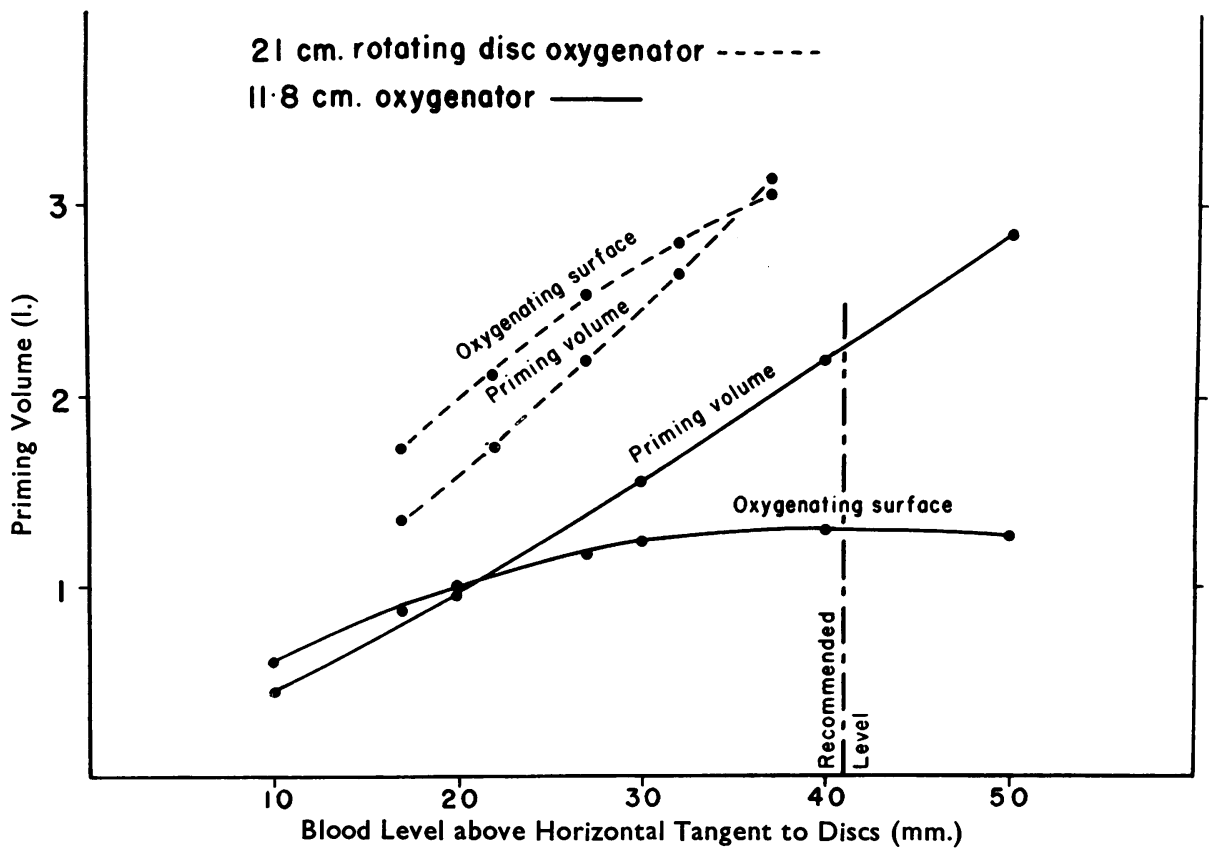

FIG. 3.-Graph showing the relationship between the priming volume and oxygenating surface of the standard and modified rotating disc $D$ oxygenator.

Figs. 1, 2, and 3 are reproduced from Osborn, Bramson, and Gerbode (1960), "A rotating disc blood oxygenator and integral heat exchanger of improved inherent efficiency," J. thorac. and cardiovasc. Surg., 39, 427, by courtesy of the C.V. Mosby Company.

(Figs. 1 to 3). However, a larger disc has a greater centrifugal force at its periphery at any given rotational speed. To prevent any additional tendency to splash and create foam, the edge of each disc was placed less than $1 / 50$ of an inch from the wall of the drum, so that a continuous meniscus was formed. This not only eliminated splashing and foaming, but coated the entire inside surface of the drum with blood, thereby increasing the oxygenating surface. The entire drum was then surrounded with a water jacket, producing a most efficient heat $\mathrm{N}$ exchanger, and one that changed the blood tempera- N ture in the same place as where the gas exchange $\omega$ occurred. The new lung (Fig. 4), which has been described in detail elsewhere (Gerbode, Osborn, $\stackrel{\circ}{ }$ Bramson, Harkins, Ross, and Johnston, $1960 ; \stackrel{\oplus}{\stackrel{\oplus}{\leftrightarrow}}$ Osborn, Bramson, and Gerbode, 1960), has been used in all perfusions carried out in this unit since 0 July, 1959. Under normothermic conditions it is $\overrightarrow{\mathbb{D}}$ capable of providing a flow rate of 2.4 to 2.8 litres $\frac{?}{\stackrel{D}{D}}$ 


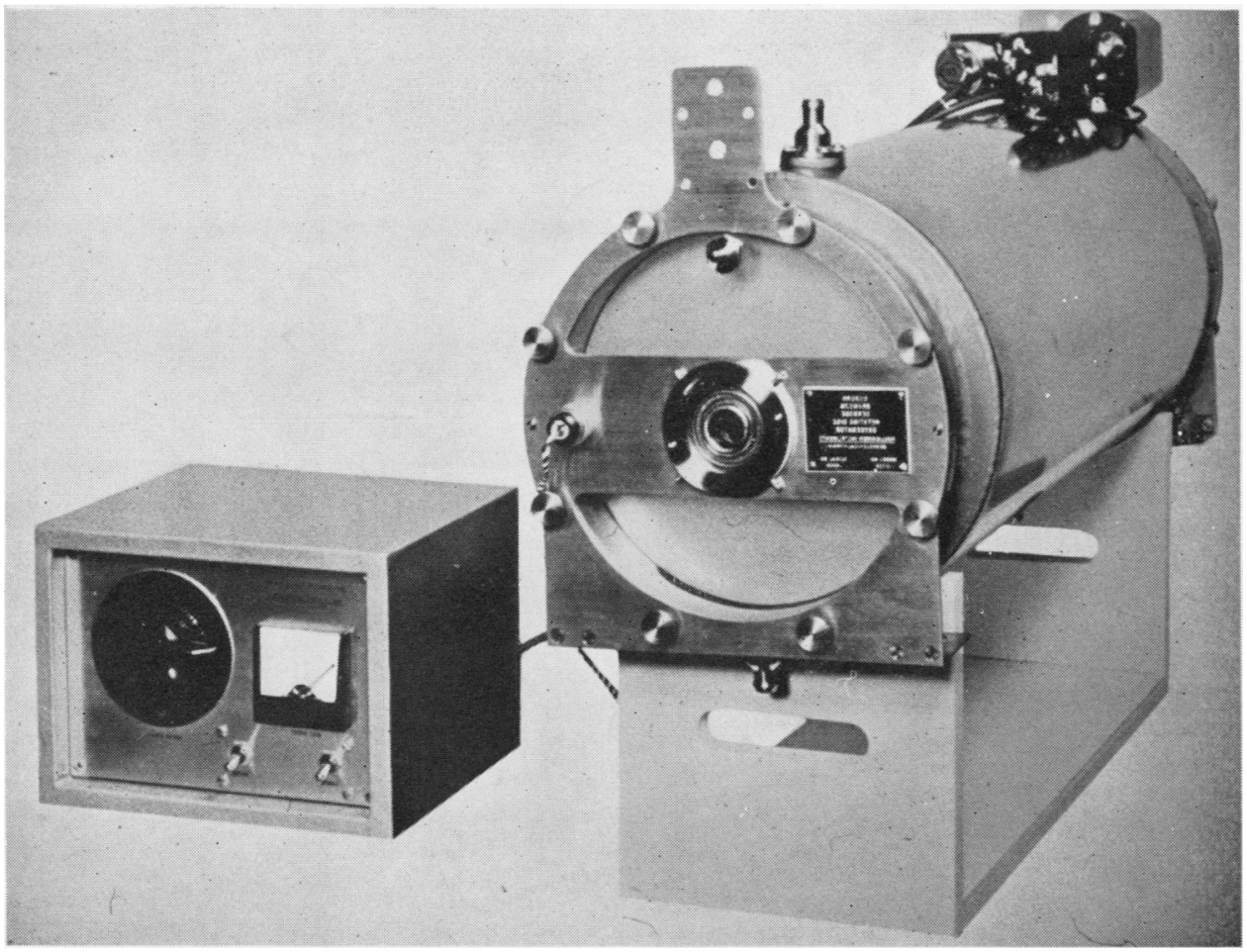

Fig. 4.-Photograph of rotating disc oxygenator with incorporated heat-exchanger as modified by Osborn, Bramson, and Gerbode.

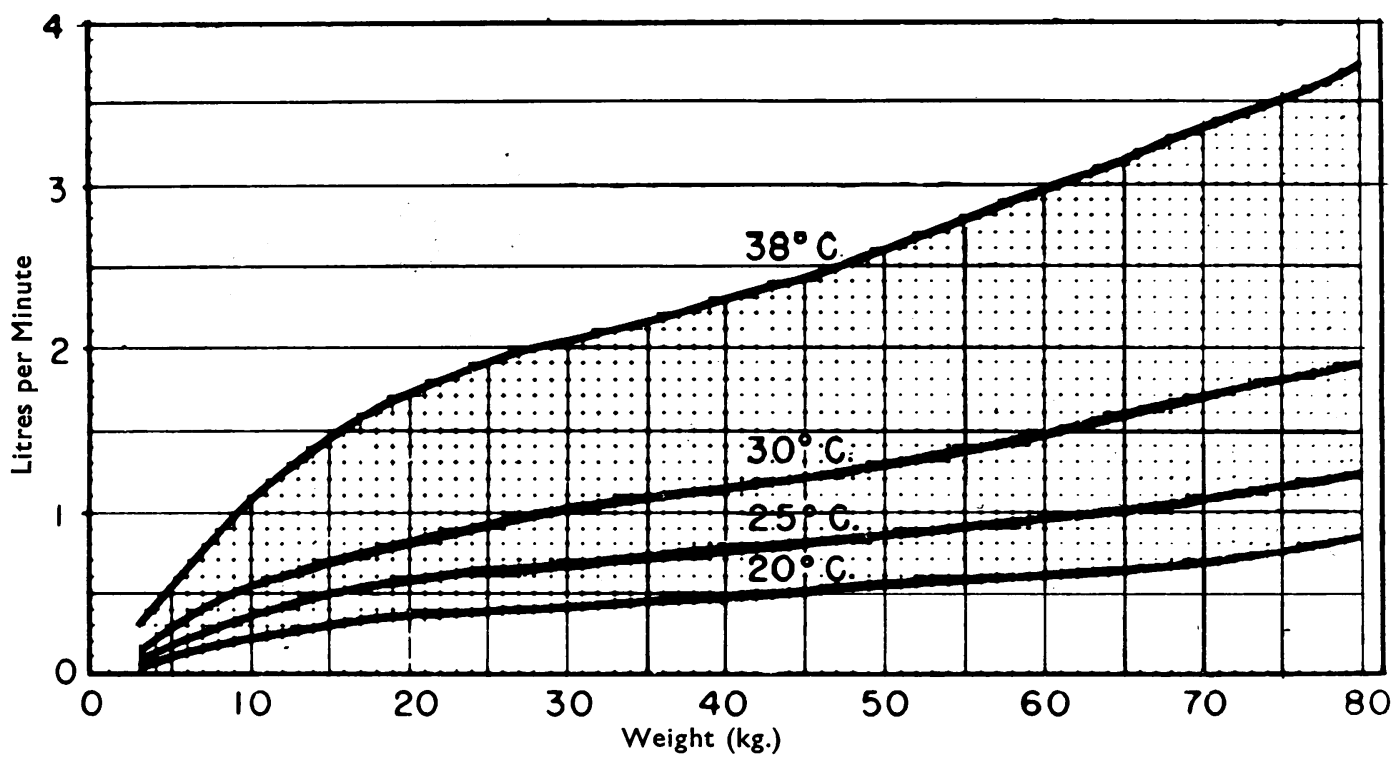

Fig. 5.-Chart illust rating the flow rate required during perfusion at various temperatures, reproduced from Gollan (1959), Physiology of Cardiac Surgery, 1st ed., by courtesy of Charles C. Thomas, Springfield, Illinois. 
per sq. metre of body surface per minute in the largest patients without foaming or desaturation.

Almost two years ago, we began exploring the use of mild hypothermia during bypass. An experience of over 100 perfusions indicated that these slightly cooled patients seemed to have a smoother and easier post-operative course. As experience was gained, the benefits of hypothermia seemed so impressive that some degree of hypothermia is now used in every perfusion.

\section{Advantages of Hypothermia in CONJUNCTION WITH OXYGENATOR}

There are several reasons why the combination might have advantages. In the first place, even with the most perfect heart lung machines, most operators concede that there are times when it is difficult to maintain an adequate perfusion. This may be because of inadequate venous drainage, or because of some other obstruction in the system, but whatever the cause the result is that in many instances the patient is perfused at a blood pressure of $80 \mathrm{~mm}$. $\mathrm{Hg}$ or less. At normal body temperatures this is really mild shock. If the patient is cooled the oxygen requirements diminish and the flow rate can be correspondingly lowered, so that at a temperature of $30^{\circ} \mathrm{C}$. an effective circulation can be maintained with an arterial pressure of $80 \mathrm{~mm}$. $\mathrm{Hg}$. This is graphically demonstrated in Fig. 5 following the work of Gollan (1959). This fact may be used to advantage in overcoming the inadequacies of some heart-lung machines.
A second benefit from a lower flow rate is the reduction in coronary and bronchial flow. It has $\stackrel{0}{\rightarrow}$ been established from studies in our laboratory that $\overline{0}$ the major source of damage to blood is in the coronary suction return. It is particularly important $\frac{\bar{\sigma}}{\bar{D}}$ in long perfusions for complicated lesions to lower $\stackrel{\mathbb{Q}}{\Omega}$ this as much as possible. It also allows the surgeon to have a clearer view of the interior of the heart.

Furthermore, it has been found that where cardio-. plegia is desirable, standstill produced by cold is $\vec{\omega}$ just as satisfactory from the surgeon's point of view $\sigma$ as that produced by potassium, but is without the $\vec{x}$ metabolic disadvantages of potassium or anoxic arrest. Long, Sterns, Gott, DeRiemes, and Lillehei $\underset{\omega}{\sigma}$ (1960) and Gott (1960) have shown that in potassium or anoxic arrest, in contrast to hypothermic cardio- o plegia, the amounts of glycogen, adenosinetriphos-윽 phate, and phosphocreatine in the myocardium are lowered and that at a certain critical level the heart is $\infty$ damaged irreversibly. Greenberg, Edmunds, and $\mathbb{D}$ Brown (1960) have further demonstrated the marked $\frac{\Phi}{3}$ impairment of cardiac function after anoxia, as assessed by left ventricular output studies. We have $\stackrel{\Phi}{-}$ not used potassium arrest, or anoxic arrest without $\vec{\bullet}$ hypothermia, in the last 225 open heart procedures.

\section{Rate AND Degree of Cooling}

Our present heat-exchanging oxygenator will coôi an adult approximately one degree a minute until low temperatures are reached. For instance, a 280-1b. man with aortic stenosis was cooled to $20^{\circ} \mathrm{C}$. in $\vec{\circ}$ 20 minutes. Rewarming is a little slower. A.s cooling 3

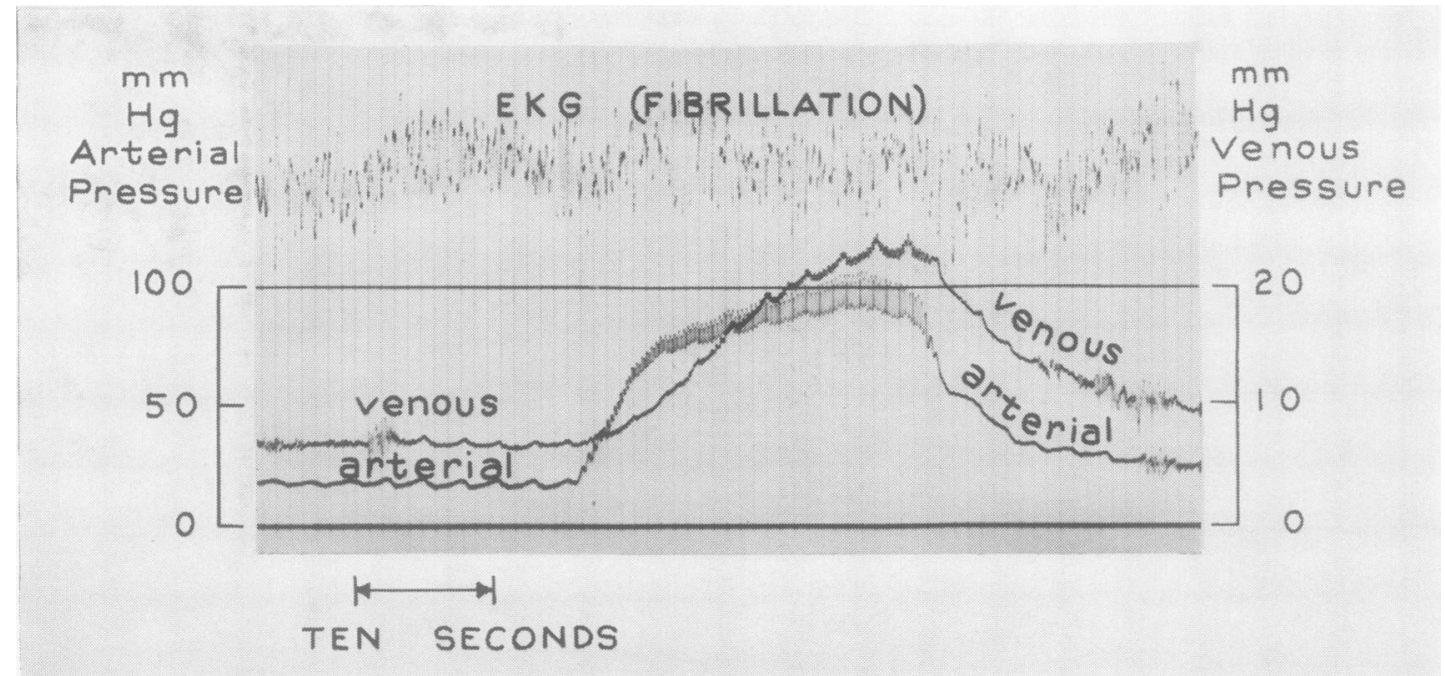

FIG. 6.-Venous and arterial pressure tracing recorded during perfusion of a patient at $16^{\circ} \mathrm{C}$. at the time when flow rate was momentarily increased to exceed capillary opening pressure. 
progresses the heart almost invariably goes into ventricular fibrillation, usually around $26^{\circ} \mathrm{C}$. On rewarming, it is found that a quarter of the patients revert spontaneously to normal sinus rhythm at a temperature near $32^{\circ} \mathrm{C}$. The others are easy to defibrillate around 32 to $33^{\circ} \mathrm{C}$. Almost all the patients have some degree of heart block at the lower temperatures, but this disappears around 34 to $36^{\circ} \mathrm{C}$.

At the present time only mild hypothermia is used for the simple lesions such as atrial septal defects. In general, the more complex the lesion, and therefore the longer the duration of the perfusion, the deeper the degree of hypothermia used. With tetralogy of Fallot, for example, cooling is carried to a temperature between 16 and $20^{\circ} \mathrm{C}$., and at this temperature a very small flow rate of half a litre per minute with an arterial pressure around 30 to $40 \mathrm{~mm}$. $\mathrm{Hg}$ would theoretically supply enough oxygen (Gollan, 1959). However, from our microscopic observations of the conjunctival circulation in hypothermic patients on perfusion, we believe that the critical opening pressure for these vessels is at least $50 \mathrm{~mm}$. $\mathrm{Hg}$. As a result, it is now our practice at these very low ranges of hypothermia to raise the pressure from 40 to $80 \mathrm{~mm}$. $\mathrm{Hg}$ every two to three minutes for a short period of time (Fig. 6).

The theoretical hazard of oxygen toxicity at low temperatures is an obvious difficulty, for the solubility of oxygen in blood is greatly increased at a low temperature and it is conceivable that this oxygen could come out of solution when it reaches the slightly warmer body. In practice, there has been no instance where we have recognized any damage from this theoretical hazard, but as a matter of principle we try to avoid an oxygen saturation over $96 \%$ in the arterial line, by reducing the disc rotation speed.

\section{Biochemical Changes During Cooling AND REWARMING}

When using perfusion hypothermia some interesting changes occur in the blood $p \mathrm{H}$, the carbon dioxide content, and potassium levels. There has been a great deal of discussion about the changes in these quotients which occur during normothermic perfusion, but there is now a considerable consensus of opinion which maintains that when such changes do occur during a normothermic perfusion it is possibly the result of inadequate perfusion with too low a flow rate. Indeed, the changes which have been described are those which would result from hypoventilation and shock in a normal person.

When starting to use this new lung it seemed sensible to maintain an approximately constant
$\mathrm{pCO}_{2}$ when cooling, and $6 \%$ carbon dioxide in oxygen was used in the oxygenator as representing an approximation of normal mixed venous $\mathrm{pCO}_{2}$. With this gas mixture, we noticed a reversal of the arterial and venous $p \mathrm{H}$ relationship as soon as cooling began, the arterial $p \mathrm{H}$ dropping strikingly below the venous level. By direct measurement of the gas entering and leaving the oxygenator, it was then found that carbon dioxide elimination from the patient not only stopped during rapid cooling, but was actually reversed, the patient absorbing large quantities of carbon dioxide as long as cooling continued. At any fixed temperature, the absorption gradually decreased and changed to elimination, the final rate of carbon dioxide elimination depending of course on the temperature reached.

It is natural to ask whether this absorption of carbon dioxide is desirable, and whether it can be prevented. When the carbon dioxide concentration in the oxygenator gas was reduced to $4 \%$, the $p \mathrm{H}$ changes, although they still occurred in the same direction, were much less striking. At the same time carbon dioxide elimination by the patient dropped almost to zero, but did not reverse to actual absorption. Experimentally it was found that the $p \mathrm{H}$ changes could be prevented by supplying the oxygenator with little or no carbon dioxide. Although this point is not settled, it is our impression that both experimental animals and patients do better if the $\mathrm{pCO}_{2}$ is maintained at somewhere between $4 \%$ and $6 \%$. It is interesting that approximately $30 \%$ of patients cooled to under $23^{\circ} \mathrm{C}$. at carbon dioxide concentrations over $4 \%$ have spontaneously recovered from ventricular fibrillation during rewarming, while this has not happened in any patients cooled with carbon dioxide concentrations of $4 \%$ and under.

During the rewarming phase of the perfusion the carbon dioxide content of the oxygenator gas must be sharply reduced. Our usual practice is to reduce it to $2 \%$. A.s soon as rewarming starts, even if it is at a very slow rate, carbon dioxide elimination by the patient increases sharply. A patient who has been cooled on $5 \%$ carbon dioxide will eliminate three or four times the normal amount of carbon dioxide during rewarming, at very high levels of $\mathrm{pCO}_{2}$. For instance, in patients cooled with $6 \%$ $\mathrm{CO}_{2}$, we have often measured outputs of carbon dioxide during rewarming of 400 or $500 \mathrm{ml}$. per minute, with mixed venous $\mathrm{pCO}_{2}$ of 11 or $12 \%$ representing 70 or $80 \mathrm{~mm}$. $\mathrm{Hg} \mathrm{pCO}$. This load of carbon dioxide represents, of course, the extra carbon dioxide absorbed during cooling, but it is important to recognize its existence, because the patient may need some help for a rather long time in its 
elimination. While the patient is still on perfusion, elimination of carbon dioxide is usually satisfactory, and respiratory acidosis is easily prevented, but if the perfusion is discontinued too soon, the patient's own circulation and lungs may not be equal to the load.

This excess elimination of carbon dioxide during rewarming continues even after operation, as the patient gradually regains normal temperature in the recovery room. Our usual findings following deep hypothermia have been a mild respiratory acidosis continuing through the end of perfusion, then a rather acute respiratory acidosis occurring as the patient takes over on his own, with a very high expired $\mathrm{pCO}_{2}$. The mixed venous $\mathrm{pH}$ may be as low as 7.2 in the first few hours in the recovery room. Except under unusual conditions, we do not treat such an acidosis with injected alkali, but rather with efforts to improve ventilation, and within six hours the mixed venous $p \mathrm{H}$ is usually returning to normal. By the following day the acidosis is usually replaced with an alkalosis with mixed venous $p \mathrm{H}$ up to 7.55 , which appears to be metabolic in type, perhaps secondary to the sodium load in the citrated blood.

Changes in serum potassium have followed in general the changes in $p \mathrm{H}$. During cooling, we have commonly found a sharp drop in serum potassium to levels near $3 \mathrm{mg}$. \%. During rewarming, the serum potassium level rises, only to fall again with the secondary respiratory acidosis when the patient returns to his own circulation. The serum potassium level may not return to normal for two days. We have the impression that digitalis must be given with caution following deep hypothermia, and we have seen patients on low doses of digitalis who produced symptoms resembling digitalis intoxication during recovery. The changes in serum potassium may explain this apparent sensitivity to digitalis. Because of these experiences, we hesitate to digitalize very rapidly or by the intravenous route following deep hypothermia. These various changes are illustrated in Figs. 7 and 8.

\section{Results of Clinical Experience with Profound PERFUSION HYPOTHERMIA}

Table I shows the number of patients who have been perfused using some degree of hypothermia.

Table II is an analysis of the temperature range reached with these various patients. In a total of 190 patients receiving some degree of hypothermia during perfusion there were 59 whose temperature was reduced to less than $29^{\circ} \mathrm{C}$.

The variety of conditions for which these 59 patients were treated is shown in Table III. Those with atrial septal defects or atrioventricular canals were cooled to about $27^{\circ} \mathrm{C}$. The temperature range used in patients suffering from ventricular septal defects was usually from 20 to $24^{\circ} \mathrm{C}$., and in patients suffering from tetralogy of Fallot the temperature level was usually 15 to $20^{\circ} \mathrm{C}$.
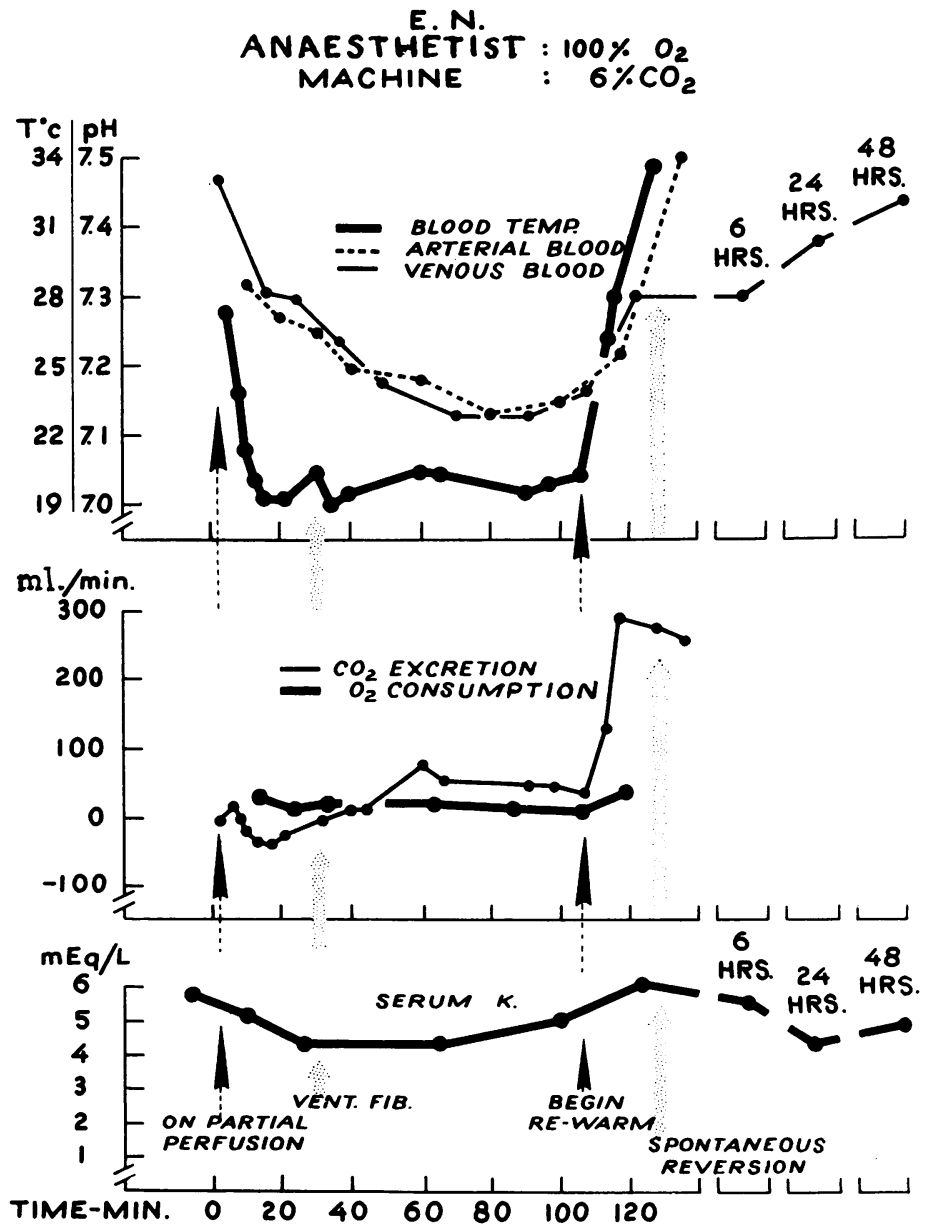

FIG. 7.-Charts from patient operated on for correction of tetralogy of Fallot illustrating changes in blood $p H$ and carbon dioxide excretion and oxygen consumption during hypothermic perfusion and in the early post-operative period. 
L.L.

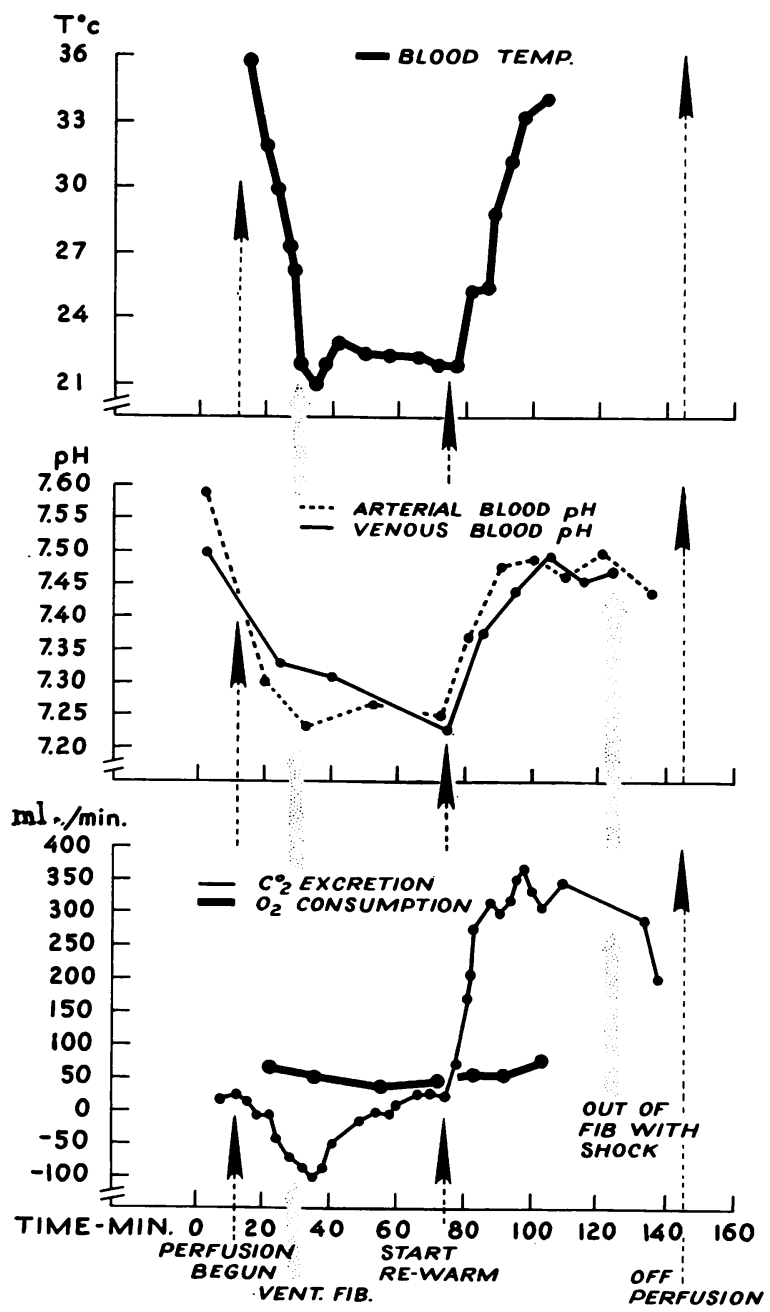

FIG. 8.-Similar charts from patient operated on for repair of ventricular septal defect using hypothermic perfusion.

TABLE I

PERFUSION HYPOTHERMIA

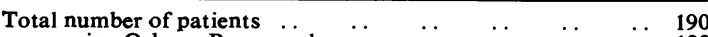
using Osborn-Bramson lung

TABLE II

DEGREE OF HYPOTHERMIA

\begin{tabular}{l|c}
\hline Temperature & Number of Patients \\
\hline $29^{\circ}-32^{\circ} \mathrm{C}$. & 131 \\
$25^{\circ}-28^{\circ} \mathrm{C}$. & 23 \\
$21^{\circ}-24^{\circ} \mathrm{C}$. & 19 \\
$13^{\circ}-20^{\circ} \mathrm{C}$. & 17 \\
\hline
\end{tabular}

TABLE III

DIFFERENT CONDITIONS IN CASES OF PRESENT SERIES

\begin{tabular}{|c|c|c|c|c|}
\hline \multicolumn{4}{|c|}{ Condition } & No. of Cases \\
\hline $\begin{array}{l}\text { Atrial septal defect } \\
\text {, ventricular canal } \\
\text { Ventricular septal defect } \\
\text { Acyanotic tetralogy } \\
\text { Tetralogy . } \\
\text { Aortic stenosis } \quad . \\
\text { Mitral incompetence } \\
\text { Miscellaneous } \quad .\end{array}$ & $\begin{array}{l}\cdots \\
\cdots \\
\cdots \\
\cdots \\
\cdots \\
\cdots\end{array}$ & $\begin{array}{l}\cdots \\
\cdots \\
\cdots \\
\cdots \\
\cdots \\
\cdots\end{array}$ & $\begin{array}{l}\cdots \\
\cdots \\
\cdots \\
\cdots \\
\cdots \\
\cdots\end{array}$ & $\begin{array}{l}6 \\
5 \\
11 \text { ( } 7 \text { high pressure) } \\
7 \\
12 \\
6 \\
3 \\
9\end{array}$ \\
\hline
\end{tabular}

TABLE IV

SURVIVAL

\begin{tabular}{|c|c|c|c|c|}
\hline & & & Number & Alive \\
\hline 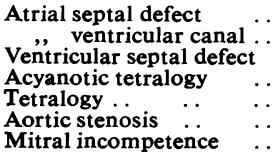 & $\begin{array}{l}\cdots \\
\cdots \\
\cdots \\
\ldots \\
\cdots\end{array}$ & $\begin{array}{l}\cdots \\
\cdots \\
\cdots \\
\cdots \\
\cdots \\
\cdots\end{array}$ & $\begin{array}{r}6 \\
5 \\
11 \\
6 \\
12 \\
6 \\
3\end{array}$ & $\begin{array}{r}6 \\
5 \\
7 \\
5 \\
10 \\
3 \\
2\end{array}$ \\
\hline
\end{tabular}

Table IV shows the results in terms of survival in patients operated upon with deep hypothermia and perfusion.

In a total of 106 atrial septal defects repaired using extracorporeal circulation, there were 65 patients operated upon with some degree of hypothermia, and there was one death in the entire group.

Apart from an improvement in survival rate, there has been a lowering of morbidity in those patients treated with a combination of hypothermia and perfusion. The patients are much more alert in the first 48 hours and feel much better. Postoperative fevers are almost unknown and the disturbance of gastro-intestinal and renal function is minimal. Only one patient developed postoperative oliguria and she recovered. The theoretical hazard of increased bleeding post-operatively due to the use of hypothermia has not been encountered. There has been no instance of permanent heart block since using this new technique.

\section{Discussion}

The combination of perfusion and hypothermia has undoubtedly improved the immediate results of intracardiac surgery in this unit. A more thorough operation under better operating conditions, and in a completely unhurried atmosphere, was made possible. It is interesting to speculate why there should have been complete absence of permanent heart block. Presumably the surgeon becomes more skilled at avoiding the conduction mechanism as his experience increases, but there is probably more to it than that. The operating conditions which are provided by the 
technique allow a much more accurate insertion of sutures. Should the mechanism be injured, the healthy metabolic state provided by perfusion hypothermia, in contrast to potassium or anoxic cardioplegia, enables it to recover more readily.

The reversal of the normal relationship of the arterial and venous $p \mathrm{H}$ on cooling is of considerable interest. The increased solubility of carbon dioxide at the lower temperatures is not enough to explain this change and it is felt that the buffer system is involved in some way.

It is not certain at the present stage whether it is better to give 4 or $6 \%$ carbon dioxide in the lung. Some degree of acidosis seems desirable at the lower temperature range and this is strongly supported by the work of Edmark (1959) in the prevention and control of ventricular fibrillation during cooling. In fact he goes so far as to add hydrochloric acid to the blood stream during cooling.

The acidosis seen in the early post-operative period is probably respiratory in origin, due to the hypoventilation which frequently occurs at this time. It is followed the next day by a metabolic alkalosis, a change of considerable practical importance, for there is a natural tendency to correct the earlier acidosis by giving alkali, which might be beneficial at the time, but the additive effect on the following day could well be lethal.

Experience with extreme hypothermia without an oxygenator has been limited to the laboratory in this unit, where it has been found to be a very useful experimental tool. It is both ingenious and extremely simple to operate, and with complete arrest of all the functions of the body the surgeon enjoys operating conditions which are normally in the province of the pathologist. We have modified the technique, using air-tight plastic bags as reservoirs, thereby eliminating air from the system, and, instead of two pumps, we use one pump with two circuits. This makes the operation of the system even more simple and reduces the chance of error to a minimum. We have extended the technique to veno-arterial cooling, which would appear to be safe for one hour at $15^{\circ} \mathrm{C}$., in the laboratory. However, there is little doubt that even at very low temperatures a certain amount of metabolic activity takes place. Provision is made for this by employing an oxygenator in combination with deep hypothermia, and continuing perfusion during the repair of the defect.

\section{SUMMARY}

A combination of cardiopulmonary bypass and hypothermia has been used in the surgical treatment of 190 patients in this unit. In 59 patients the body temperature has been lowered to levels between 15 and $28^{\circ} \mathrm{C}$.

The theoretical advantages of this approach are discussed, and the improved survival rate and lowered morbidity would appear to justify continuing this technique.

Changes in the levels of the $p \mathrm{H}$, carbon dioxide content, and potassium in the blood serum were noted and the importance of these changes is discussed.

\section{REFERENCES}

Bigelow, W. G., Lindsay, W. K., and Greenwood, W. F. (1950) Ann. Surg., 132, 849.

Drew, C. E., and Anderson, I. M. (1959). Lancet, 1, 748.

Keen, G., and Benazon, D. B. (1959). Ibid., 1,745.

Edmark, K. W. (1959). Surg. Gynec. Obstet., $109,743$.

Gerbode, F., Osborn, J. J., Bramson, M. L., Harkins, G. A., Ross, J. K., and Johnston, J. B. (1960). Amer. J. Surg., 100, 338. - Melrose, D. G., Perkins, H. A., Norman, A., and Baer, D. M. (1958). Lancet, 2, 284.

Gollan, F. (1959). Physiology of Cardiac Surgery. Thomas, Springfield, Illinois.

Gott, V. L. (1960). Symposium on Extreme Hypothermia. Amer. Coll. of Cardiology, Indianapolis.

Greenberg, J. J., Edmunds, L. H., Jr., and Brown, R. B. (1960) Surgery, 48, 31 .

Lewis, F. J., Varco, R. L., and Taufic, M. (1954). Ibid., 36, 538.

Long, D M Sterns, L. P. Gott, V. L. DeRiemes, R. H., and Lillehei, C. W. (1960). Read at Annual Meeting of Amer. Ass. for Thorac. Surg., Miami Beach.

Miller, B. J., Gibbon, J. H., Jr., and Fineberg, C. (1953). Med. Clin. N. Amer., 37, 1603.

Osborn, J. J., Bramson, M. L., and Gerbode, F. (1960). J. thorac. and cardiovasc. Surg., $39,427$.

Shields, T. W., and Lewis, F. J. (1959). Surgery, 46, 164.

Swan, H., Zeavin, I., and Blount, S. G., Jr. (1953). J. Amer. med. Ass., 153, 1081 . 